\title{
Bazı Yonca Çeşitlerinin Erken Gelişme Dönemindeki Kuraklık Toleransının Belirlenmesi
}

\author{
Mahir ÖZKURT ${ }^{1} \mathscr{P}$ (D), İbrahim SAYGILI ${ }^{2}$ D), Kübra ÖZDEMİR DİRİK ${ }^{2}$ (D) \\ ${ }^{1}$ Muş Alparslan Üniversitesi Uygulamalı Bilimler Fakültesi Bitkisel Üretim ve Teknolojileri Bölümü, Muş, ${ }^{2,3}$ Tokat Gaziosmanpaşa \\ Üniversitesi Ziraat Fakültesi Tarla Bitkileri Bölümü, Tokat \\ ${ }^{1}$ https://orcid.org/0000-0003-0058-3026, ${ }^{2}$ https://orcid.org/0000-0003-0449-4872, ${ }^{3}$ https://orcid.org/0000-0002-6901-561X \\ $\bowtie$ : mahirozkurt@gmail.com
}

\section{ÖZET}

Kurak ve yarı kurak alanlarda yeterli çimlenmeyi kısıtlayan önemli faktörlerinden biri su varlığının çok az olmasıdır. Sulama imkanının kısıtlı olduğu bölgelerde daha uygun genotiplerin kullanılması iyi bir çıkışın ön şartıdır. Bu araştırma, Türkiye'de yetiştiriciliği yapılan bazı yonca çeşitlerinin erken dönem kuraklık stresine toleransını belirlemek amacıyla yapılmıştır. Araştırmada on sekiz yonca çeşidi petri kaplarında polietilenglikol 6000 kullanılarak oluşturulan farklı konsantrasyonlarda ( -3 bar ve -6 bar) erken kuraklık stresine tabi tutulmuştur. Araştırmanın 7. gününde çimlenme oranı, kök uzunluğu, vigor indeksi, çimlenme hızı ve çimlenme indeksi belirlenmiştir. Artan kuraklık stresi fide gelişimini önemli derecede kısıtlamıştır. Çimlenme oranları kontrole göre -3 bar kuraklık stresinde \%9.9, -6 bar kuraklık stresinde \%88.6 oranında azalmıştır. İncelenen çeşitler arasında Sabrina, Elçi ve Frigos çeşitlerinin çimlenme oranlarına göre erken gelişme döneminde kuraklık stresine toleranslı olduğu, Magna 601, Victoria ve Sunter çeşitlerinin ise kuraklık stresine toleranslı olmadığı belirlenmiştir. İncelenen bütün karakterler dikkate alındığında Sabrina kuraklığa en toleranslı çeşit olarak değerlendirilebilir. Sulama ve kisitlı sulama problemi olan bölgeler için tavsiye edilebilecek bu çeşidin, sulama sıkıntısı olan bölgelerde tarla denemelerine dahil edilmesi, bu bölgelerde yonca üretimini geliştirilmesine katkı sağlayacaktır.
Araştırma Makalesi

Makale Tarihçesi

Geliş Tarihi : 01.02.2019

Kabul Tarihi : 15.03 .2019

Anahtar Kelimeler
Osmotik stres
Çimlenme oranı
Çimlenme hızı
Vigor indeksi

Anahtar Kelimeler

Osmotik stres

Çimlenme oranı

Vigor indeksi

\section{Determining the Drought Tolerance of Some Alfalfa Cultivars in Early Growth Stage}

\section{ABSTRACT}

Low water availability is one of the important factors limiting adequate germination in arid and semi-arid areas. In these areas, the use of more suitable genotypes is a prerequisite for good germination. The research was conducted to determine the drought tolerance of some alfalfa cultivars grown in Turkey. In this study, eighteen alfalfa cultivars were subjected to drought stress stimulated by Polyethylene Glycol 6000 in various levels (-3 and -6 bar) in petri dishes. Germination percentage, radicle length, vigor index, germination rate and germination index were investigated in the 7th days. Increased levels of drought stress have been significantly reduced seedling growth. Germination percentage were decreased by $9.9 \%$ in -3 bar, $88.6 \%$ in -6 bar compared to the control. Cultivars Sabrina, Queen and Frigos were more tolerant to drought than other cultivars investigated, while cultivar Magna 601, Victoria and Sunter were susceptible. Considering all the characteristics, Sabrina can be considered as the most tolerant to drought. The inclusion of cultivar Sabrina to field experiment to be conducted in the region with restricted irrigation will contribute to the development of alfalfa production in these regions.

\section{Research Article}

$\begin{array}{ll}\text { Article History } & \\ \text { Received } & : 01.02 .2019 \\ \text { Accepted } & : 15.03 .2019\end{array}$

\author{
Keywords \\ Osmotic stress \\ Germination rate \\ Germination speed \\ Vigor index
}

To Cite : Özkurt M, Saygılı İ, Özdemir Dirik K 2019. Bazı Yonca Çeşitlerinin Erken Gelişme Dönemindeki Kuraklık Toleransının Belirlenmesi. KSÜ Tarım ve Doğa Derg 22(4): 558-563. DOI: 10.18016/ksutarimdoga.vi.521101 


\section{GİRIŞ}

Yaygin yonca (Medicago sativa L.) hem dünyada hem de Türkiye'de yem bitkileri içerisinde en fazla yetiştiriciliği yapılan uzun ömürlü çok yıllık bir bitkidir (Ö̈zkurt, 2018). Adaptasyon yeteneğinin yüksek olmasından dolayı yem bitkilerinin kraliçesi olarak değerlendirilmektedir. Yoncanın yüksek olan adaptasyon kabiliyeti tarımsal üretimin yüksek performans ile yapıldığı sulak alanlardan, kuraklık stresinin daha yoğun görüldüğü bölgelere kadar tercih edilmesine neden olmaktadır. Kısmen sulanabilen kurak bölgelerde bile alternatifsiz kalan yonca üretiminin, ekiminden hasadına kadar daha arzulanır olması için bu bölgelere uygun çeşitlerin tercih edilmesini gerektirmektedir.

Tarımsal üretimi etkileyen en önemli stres faktörlerinden biri olan (Kalefetoğlu ve Ekmekçi, 2005) kuraklığın şiddeti, yağışlarla alınan suyun miktarı yanında, kullanılan çeşide, toprağın su tutma kapasitesine, sicaklık ve bulutluluk gibi faktörlere de bağlıdır (Saxena ve ark., 1993). Tarımsal üretim üzerine kuraklığın önemli etkilerinden biri ekimden sonra optimum çıkış sağlayamamadır (Saxena ve ark., 1993). Kuraklık stresi genellikle çimlenme sürecinin gecikmesine neden olmakta ve çimlenme yüzdesini, çimlenme hızını ve büyüme oranını önemli ölçüde azaltmaktadır (Hamidi, 2000). Kuraklık stresinin çimlenme evresinde meydana getireceği kayıpların önemli boyutlara varabileceği ve söz konusu stres faktörlerine toleranslı yeni genotiplerin kullanılması verim ve kalite açısından büyük önem arz etmektedir (Kaplan ve ark., 2015).

Birçok üründe olduğu gibi yoncada da gün geçtikçe çeşitler ıslah edilip, tarımsal üretimin hizmetine sunulmaktadır. Geliştirilen çeşitlerin bölgelere uyumu, stres faktörlerine tepkilerinin belirlenmesi ve uygun olanların seçilmesi yonca tarımının gelişmesine katkı sağlamaktadır. Çarpıcı ve Erdel, (2015) bazı yonca çeşitlerinin kuraklık stresine verdiği tepkiyi belirledikleri araştırmalarında, çimlenme, kök ve sap uzunluğu ile fide gücü (vigor) bakımından önemli farklılıkların olduğu ve Bilensoy-80 ve Alsancak yonca çeşitlerinin çimlenme ve erken fide dönemindeki kuraklık stresini daha iyi tolere edebildikleri belirlemişlerdir. $\mathrm{Bu}$ araştırmanın amacı, ülkemizde yetiştiriciliği yapılan ve yeni piyasaya sürülen bazı yonca çeşitlerinin erken dönemde kuraklığa toleranslarının belirlenmesidir. Yeni geliştirilen yonca çeşitlerinin erken dönemdeki kuraklık toleransının belirlenmesi, kuraklığa karşı alınabilecek en etkili önlemlerden biri olan dayanıklı çeşit seçimine katkı sağlayacaktır.

\section{MATERYAL ve METOD}

Araştırma 2018 yılında Gaziosmanpaşa Üniversitesi Ziraat Fakültesi Tarla Bitkileri Bölümü Yem Bitkileri Laboratuvarında yürütülmüştür. $\mathrm{Bu}$ çalışmada ülkemizde tescilli 18 yonca çeşidi kullanılmıştır (Çizelge 1).

Çimlendirme öncesi tohumlar yüzey strelizasyonu için $\% 1$ lik sodyum hipoklorit çözeltisinde $5 \mathrm{dk}$ sterilize edilmiş ve $3 \mathrm{kez}$ saf su ile durulanmıştır. Havada kurutulan tohumlar, iki kat filtre kağıdı bulunan 9 $\mathrm{mm}$ çapında petri kaplarına yerleştirilmiştir. Kontrol uygulaması için steril saf su ve ozmotik stres için -3 bar (151.3 g/litre) ve -6 bar (223.6 g/litre) polyethylene glycol 6000 (PEG 6000) kullanılmıştır (Torabi ve ark. 2011).

Çizelge 1. Çalışmada kullanılan yonca çeşitleri ve tescil edildiği kurum/kuruluşlar

\begin{tabular}{llc}
\hline Çeşit adı & Tescil edildiği Kurum/Kuruluşlar & Tescil/Üretim izin yılı \\
\hline Bilensoy-80 & Tarla Bitkileri Merkez Araştırma Enstitüsü & 1984 \\
Derby & Beta Ziraat ve Ticaret A.Ş & 2006 \\
Elçi & Ankara Üniversitesi & 1993 \\
Escorial & Aday Çeşit I & - \\
Ezzelina & Alfa Tohum & 2019 \\
Fito Altiva & Fito tohumculuk & 2011 \\
Frigos & Yonca Tohumculuk & 2016 \\
İside & May-Agro Tohum Sanayi ve Tic. & 2013 \\
MA-414 & May-Agro Tohum Sanayi ve Tic. & 2012 \\
Magna 601 & Biotek Tohum ve Tarım Ürünleri Ltd.Şti & 2012 \\
Nimet & Doğu Akdeniz Tarımsal Araştırma Enstitüsü & 2011 \\
Plato & Kazak Tarım Inş̧. Tic. A.Ş & 2012 \\
Prosementi & Tasaco Tarım Sanayi Tic. Ltd. Şti & 2008 \\
Queen & Neobi Tohumculuk A.Ş & 2010 \\
Sabrina & Aday Çeşit II & - \\
Savaş & Doğu Akdeniz Tarımsal Araştırma Enstitüsü & 2003 \\
Sünter & Mutlu Tohum Sanayi Tic. & 1984 \\
Victoria & Fito Tohumculuk & 2011 \\
\hline
\end{tabular}


Her bir petri kabina 50 adet tohum, her bir PEG konsantrasyondan $4 \mathrm{ml}$ kullanılmıştır ve bu süreç buharlaşan suyu yenilemek için 2 günde bir tekrarlanmıştır. Petri kaplarının kapakları buharlaşmayı engellemek amacıyla parafilm ile sarılmıştır. Petri kapları karanlık ortamda $20 \pm 1{ }^{\circ} \mathrm{C}$ sıcaklıkta muhafaza edilmiştir. Tüm tohumlar 10 günlük çimlenme periyodu boyunca her gün sayılmış ve $2 \mathrm{~mm}$ radikula çıkaran tohumlar çimlenmiş kabul edilmiştir (Çarpıcı ve Erdel, 2015). Araştırmada çimlenme yüzdesi, çimlenme hızı ve radikula uzunluğu Soltani ve ark. (2012)'na, vigor indeksi Hamidi ve Safarnejad, (2010)'a çimlenme indeksi ise Torabi ve ark. (2011)'e göre belirlenmiştir.

Deneme tesadüf parselleri faktöriyel deneme desenine göre 3 tekerrürlü olarak yürütülmüştür. Elde edilen verilerin istatistik analizi MSTAT-C istatistik paket programı kullanılarak analiz edilmiş ve ortalamalar arası farklılıklar LSD testi ile belirlenmiştir. Yüzde oranlar açı transformasyonuna tabi tutularak istatistik analiz edilmiş, orijinal değerler verilmiştir (Soltani ve ark. 2012).

\section{BULGULAR ve TARTIŞMA}

\section{Çimlenme Yüzdesi (\%)}

Araştırmada incelenen çeşitlerin final çimlenme yüzde değerlerine uygulanan varyans analiz sonuçlarına göre incelenen çeşitler arasında önemli $(\mathrm{P} \leq 0.01)$ farklılıklar bulunmuştur (Çizelge 2).

Çizelge 2. Araştırmadan elde edilen ortalama final çimlenme yüzdeleri (\%) ve kök uzunlukları (mm)

\begin{tabular}{|c|c|c|c|c|c|c|c|c|}
\hline \multirow[b]{2}{*}{ Ceşitler } & \multicolumn{4}{|c|}{ Final Çimlenme oranı (\%) } & \multicolumn{4}{|c|}{ Kök Uzunluğu (mm) } \\
\hline & Kontrol & 3 bar & 6 bar & Ort. & Kontrol & $3 \mathrm{bar}$ & $6 \mathrm{bar}$ & Ort. \\
\hline Bilensoy-80 & $79.3 \mathrm{f}^{-} 1^{*}$ & $60.0 \mathrm{jk}$ & $14.7 \mathrm{o}$ & $51.3 c d e^{1}$ & $52.3 \mathrm{abc}^{*}$ & $26.3 \mathrm{ljk}$ & $7.5 \mathrm{n}^{-} \mathrm{s}$ & $28.7 c d^{1}$ \\
\hline Derby & $71.3 \mathrm{hij}$ & $68.7 \mathrm{ij}$ & $3.3 \mathrm{q}^{-\mathrm{t}}$ & $47.8 \mathrm{e}$ & $43.0 \mathrm{def}$ & $26.6 \mathrm{ijk}$ & $1.5 \mathrm{~s}$ & $23.7 \mathrm{ef}$ \\
\hline Elçi & $95.3 \mathrm{ab}$ & $90.7 \mathrm{a}^{-\mathrm{e}}$ & $0.0 \mathrm{t}$ & $62.0 \mathrm{~b}$ & $45.4 \mathrm{~b}-\mathrm{f}$ & $22.7 \mathrm{jkl}$ & $0.0 \mathrm{~s}$ & $22.7 \mathrm{fgh}$ \\
\hline Escorial & $83.3 \mathrm{~d}-\mathrm{h}$ & ו־-1 & 10.7 op & $58.7 b c$ & $40.3 \mathrm{efg}$ & $28.5 \mathrm{jjk}$ & $6.9 \mathrm{o}^{-\mathrm{s}}$ & $25.3 \mathrm{def}$ \\
\hline Ezzelina & $94.0 \mathrm{abc}$ & $86.0 \mathrm{c}^{-} \mathrm{g}$ & $2.0 q^{-\mathrm{t}}$ & $60.7 \mathrm{~b}$ & $43.8 c^{-} \mathrm{g}$ & $23.2 \mathrm{jkl}$ & 3.3 qrs & $23.4 \mathrm{efg}$ \\
\hline Fito Altiva & 81.3 e-^ & $44.0 \mathrm{~lm}$ & $10.0 \mathrm{op}$ & $45.1 e$ & $37.2 \mathrm{fgh}$ & $22.9 \mathrm{jkl}$ & $2.8 \mathrm{qrs}$ & $21.0 \mathrm{fgh}$ \\
\hline Frigos & $94.0 \mathrm{abc}$ & $92.0 \mathrm{a}-\mathrm{d}$ & $15.3 \mathrm{o}$ & $67.1 \mathrm{a}$ & $47.0 \mathrm{~b}-\mathrm{e}$ & $34.5 \mathrm{gh}$ & $5.8 \mathrm{p}^{-\mathrm{s}}$ & $29.1 \mathrm{~cd}$ \\
\hline İside & $89.3 \mathrm{~b}-\mathrm{f}$ & $84.0 \mathrm{~d}-\mathrm{h}$ & $6.7 \mathrm{pqr}$ & $60.0 b c$ & $44.2 \mathrm{c}-\mathrm{f}$ & $37.3 \mathrm{fgh}$ & $7.4 \mathrm{n}^{-\mathrm{s}}$ & $29.6 \mathrm{~cd}$ \\
\hline MA-414 & $69.3 \mathrm{ij}$ & $41.3 \mathrm{~lm}$ & $26.0 \mathrm{n}$ & $45.6 e$ & $30.7 \mathrm{hij}$ & $28.5 \mathrm{ljk}$ & $6.6 \mathrm{o}^{-\mathrm{s}}$ & $21.9 \mathrm{fgh}$ \\
\hline Magna 601 & $36.7 \mathrm{lmn}$ & $51.3 \mathrm{kl}$ & $0.0 \mathrm{t}$ & $29.3 f$ & $15.8 \mathrm{lmn}$ & 15.0 l-o & $0.0 \mathrm{~s}$ & 10.31 \\
\hline Nimet & $85.3 \mathrm{c}^{-} \mathrm{g}$ & ב־- 82.7 ( & 8.7 opq & $58.9 b c$ & $49.1 \mathrm{a}-\mathrm{d}$ & $28.4 \mathrm{jjk}$ & $13.0 \mathrm{~m}-\mathrm{p}$ & 13.81 \\
\hline Plato & $82.0 \mathrm{~d}-1$ & $78.7 \mathrm{f}-1$ & $2.7 \mathrm{rst}$ & $54.4 d e$ & $49.1 \mathrm{a}-\mathrm{d}$ & $30.9 \mathrm{hij}$ & $2.5 \mathrm{rs}$ & $27.5 \mathrm{cde}$ \\
\hline Prosementi & $75.3 \mathrm{gh} ı$ & $63.3 \mathrm{gh}$ & 13.3 o & $50.7 \mathrm{bcd}$ & $53.7 \mathrm{ab}$ & $37.5 \mathrm{fgh}$ & $14.1 \mathrm{~m}-\mathrm{p}$ & $35.1 a b$ \\
\hline Queen & $82.0 \mathrm{~d}-1$ & ו-1- 82.7 & $8.7 \mathrm{op}$ & $57.8 \mathrm{bcd}$ & $52.0 \mathrm{abc}$ & 30.5 hij & $10.8 \mathrm{n}-\mathrm{r}$ & $31.1 b c$ \\
\hline Sabrina & $96.7 \mathrm{a}$ & $95.3 \mathrm{ab}$ & $12.7 \mathrm{o}$ & $68.2 \mathrm{a}$ & $56.4 \mathrm{a}$ & $41.4 \mathrm{~d}-\mathrm{g}$ & $11.4 \mathrm{n}^{-} \mathrm{q}$ & $36.4 a$ \\
\hline Savaş & $89.3 \mathrm{~b}-\mathrm{f}$ & $88.0 \mathrm{~b}-\mathrm{f}$ & $5.3 \mathrm{p}-\mathrm{s}$ & $60.9 \mathrm{~b}$ & $49.9 \mathrm{a}-\mathrm{d}$ & $48.0 \mathrm{a}^{-\mathrm{e}}$ & $12.8 \mathrm{~m}-\mathrm{p}$ & $36.9 \mathrm{a}$ \\
\hline Sünter & $47.3 \mathrm{klm}$ & $45.3 \mathrm{~lm}$ & $0.7 \mathrm{st}$ & $31.1 f$ & 33.6 ghı & $20.8 \mathrm{klm}$ & $1.7 \mathrm{~s}$ & $18.7 \mathrm{gh}$ \\
\hline Victoria & $39.3 \mathrm{~lm}$ & $33.3 \mathrm{mn}$ & $2.7 \mathrm{rst}$ & $25.1 f$ & $26.7 \mathrm{jjk}$ & $25.8 \mathrm{ijk}$ & 3.2 qrs & $18.5 \mathrm{~g}$ \\
\hline Ort. & $78.3 \mathrm{~A}^{+}$ & $70.5 \mathrm{~B}$ & $8.0 \mathrm{C}$ & & $40.1 A^{+}$ & $29.4 B$ & $6.2 C$ & \\
\hline
\end{tabular}

*Aynı sütun içerisinde benzer harf ile gösterilen ortalamalar. Duncan testine göre. $\mathrm{P} \leq 0.01$ hata sınırları içerisinde birbirlerinden farksızdır.

+Aynı satır içerisinde benzer harf ile gösterilen ortalamalar. Duncan testine göre. $\mathrm{P} \leq 0.01$ hata sınırları içerisinde birbirlerinden farksızdır.

${ }^{1}$ Aynı sütun içerisinde benzer harf ile gösterilen ortalamalar. Duncan testine göre. $\mathrm{P} \leq 0.01$ hata sınırları içerisinde birbirlerinden farksızdır.

Çeşitlerin ortalama final çimlenmesi yüzdeleri \%25.1 ile \%68.2 arasında değişmiş ve en yüksek final çimlenme yüzdesi Frigos ve Sabrina çeşitlerinden elde edilmiştir. Kontrol uygulamasından ortalama \%78.3 olan final çimlenme yüzdesi artan PEG konsantrasyonlarında istatistiki olarak önemli derecede azalmış ve -6 bar PEG konsantrasyonunda \%8.0'a kadar düşmüş ve bu osmotik stres uygulamasından elde edilen ortalama çimlenme yüzdesi istatistiki olarak en düşük istatistiksel grubu oluşturmuştur. Araştırma sonucunda osmotik stres uygulamasının -3 bar PEG konsantrasyonuna düşmesi bazı çeşitlerde çimlenme oranları açısından kontrol uygulamasına göre istatistiki olarak bir fark oluşturmamıştır. Nitekim kontrol uygulamasında
Sabrina, Frigos, Savaş çeşitlerinin çimlenme yüzdeleri ile (sirasiyla \%96.7, 94.0 ve 89.3), - 3 bar PEG uygulamasından elde edilen çimlenme yüzdeleri (sirasıyla \%95.3, 92.0 ve 88.0) arasında istatistiki olarak önemli derecede fark oluşmamıştır. Ancak -6 bar osmotik stres uygulaması tüm çeşitlerin çimlenme yüzdelerinde \%36.6-95.3 arasında değişen oranda azalmalara neden olmuştur (Çizelge 2). Araştırmadan elde edilen değerler bazı araştırıcıların elde ettikleri değerler ile uyum içerisindedir ( Budaklı Çarpıcı ve Erdel, 2015; Hamidi ve Safarnejad ,2010; Tilaki ve ark., 2009; Feng ve ark., 2018; Safarnejad, 2008). Çimlenme yüzdesi özellikle yonca gibi küçük tohumlu bitkilerin performansını değerlendirmede önemli bir kriterdir. Çimlenme yüzdesi göz önünde 
bulundurulduğunda Frigos ve Sabrina çeşitlerinin diğer çeşitlere göre bu şartlara daha toleranslı olduğu söylenebilir.

\section{Kök Uzunluğu (mm)}

Araştırmada incelenen çeşitlerin kök uzunluğu yüzde değerlerine uygulanan varyans analiz sonuçlarına göre incelenen çeşitler arasında çok önemli (0.01) farklılıklar bulunmuş, kök uzunlukları $10.3 \mathrm{~mm}$ ile $36.9 \mathrm{~mm}$ arasında değişmiştir (Çizelge 2). En yüksek kök uzunlukları aynı istatistiki grubu oluşturan Sabrina, Savaş ve Prosementi çeşitlerinden elde edilmiştir. Bu durum bu çeşitlerin diğer çeşitlere göre kök uzunlukları bakımından üstün olduklarını göstermektedir. Kontrol uygulamasında $40.1 \mathrm{~mm}$ olan ortalama kök uzunluğu artan PEG konsantrasyonunda istatistiki olarak önemli derecede azalmış ve -6 bar PEG uygulamasında ise $6.2 \mathrm{~mm}$ 'ye kadar düşmüş ve söz konusu PEG uygulamasında istatistiki olarak en düşük istatistiksel grubu oluşturmuştur. PEG konsantrasyonunun -3 barlık kuraklık stresinde Savaş ve Victoria çeşitleri kontrol uygulamasına göre istatistiksel olarak farklı olmazken, diğer çeşitler istatistiksel olarak önemli derecede azalma göstermiştir. Kuraklık stresinin -6 bar seviyesi ise kök uzunluğu üzerine gerek -3 bar gerekse kontrol uygulamasına göre istatistiksel olarak önemli derecede azalmaya neden olmuştur. Araştırma sonucunda elde edilen bulgular bazı araştırıcıların (Hesabi ve ark. 2014; Hashang ve Mohsen, 2013; Carmen ve Nedelea, 2012 ve Hamidi ve Safarnejad, 2010.) elde ettikleri bulgular ile benzerlik göstermektedir. Budaklı Çarpıcı ve Erdel (2015), aralarında bu araştırmada kullanılan yonca çeşitlerinin de bulunduğu beş farklı yonca çeşidi ile yapığı araştırmalarında, ortalama kök uzunluklarını 0.00-54.45 $\mathrm{mm}$ arasında tespit etmiştir. Aynı araştırmada kuraklık stresi arttıkça ortalama kök uzunluklarının da arttığını belirlenmiştir. Araştırmamızdan elde edilen bulgular ise artan kuraklık stresinde ortalama kök uzunluğunun azaldığını göstermektedir. Bu kuraklık stresi altında kök uzunluklarının değişkenlik göstermesine, araştırmada kullanılan PEG konsantrasyonundaki farklılığın neden olduğunu söylenebilir. Daha yoğun kullanılan PEG şartlarında bile bazı çeşitlerdeki kontrole göre azalmanın olmaması, kurak bölgelerde derinlerde bulunan suya ulaşma bakımından bu çeşitleri avantajlı yapmaktadır.

\section{Vigor İndeksi}

Vigor indeksi değerlerine uygulanan varyans analizi sonuçlarına göre incelenen çeşitler. vigor indeksi ortalama değerlerinde istatistiki bir farklılık oluşturmuş̧ur ( $\mathrm{P} \leq 0.01$, Çizelge 3 ). Çeşitlerin farklı kuraklık stresi altında elde edilen ortalama vigor indeksi kontrol uygulamasında 32.3 olmuş, ortalama vigor indeksi artan kuraklık stresinde azalmış (21.6 ve 0.7 ) ve bu azalış istatistiki olarak önemli farklılık meydana getirmiştir. Elde edilen vigor indeksi değerleri incelendiğinde araştırmadan elde edilen vigor indeksi değerleri 0.00 ile 54.5 arasında değişmiş ve bu değişimin istatistiki olarak önemli olduğu tespit edilmiştir. Çeşitler arasında en düşük vigor indeksi Sünter, Victoria ve Magna 601 çeşitlerinde belirlenmiştir. En yüksek vigor indeksi değerini ise 31.8 ile Sabrina çeşidi vermiştir. Artan kuraklık stresi ortalama vigor indeksi değerlerinin düşmesine neden olmuş ve bu olumsuz etki istatistiksel olarak önemli derecede farklılık göstermiştir. Benzer bulgular bazı araştırıcılar tarafından elde edilmiştir (Feng ve ark., 2018; Budaklı Çarpıcı ve Erdel, 2015). Araştırmadan elde edilen değerlere göre kuraklık stresinin artması vigor indeksi değerlerinin düşmesine neden olmuştur. Nitekim Budaklı Çarpıcı ve Erdel (2015) araştırmalarında artan kuraklık stresinin vigor indeksi değerinin azalmasına neden olmuş ve bu bulgu araştırmamızı destekler niteliktedir. Vigor indeksi değeri çimlenme oranı değerlerinde formül ile hesaplandığından dolayı çimlenme oranı değerleri ile paralellik göstermesi beklenen bir durumdur. Sabrina ve Frigos çeşitlerinin diğer çeşitlere göre çimlenme yüzdesinde olduğu gibi vigor indeksi bakımından daha üstün oldukları görünmektedir. -3 bar PEG uygulamasında vigor indeksi değerleri bazı çeşitlerde çok fazla bir değişiklik meydana getirmemiş ve hatta Savaş çeşidinde istatistiksel olarak etkilememiştir. Bu durum vigor indeksi bakımından çeşitlerin tolerans sinırı olarak - 3 bar PEG konsantrasyonu olduğunu söylemek mümkündür. Vigor indeksi parametresinin çimlenme oranları kullanılarak hesaplanmasından dolayı çimlenme yüzdesinde öne çıkan çeşitlerin vigor indeksinde de öne çıkması beklenen bir durumdur.

\section{Çimlenme İndeksi}

Araştırmada incelenen çeşitlerin çimlenme indeksi değerlerine uygulanan varyans analiz sonuçlarına göre incelenen çeşitler arasında çok önemli farklılıklar bulunmuştur. Çeşitlerin ortalama çimlenme indeksi 35.1 ile 85.3 arasında değişiklik göstermiş ve bu değişim istatistiksel olarak önemli bulunmuştur (Çizelge 3).

Çeşitlere uygulanan kuraklık stresi çeşitlerin ortalama çimlenme indeksi değerlerini istatistiksel olarak önemli $(\mathrm{P} \leq 0.01)$ derecede etkilemiştir. Kontrol uygulamasında 82.2 olan çimlenme indeksi - 3 bar PEG kuraklık stresi uygulamasında 89.9, -6 PEG kuraklık stresi uygulamasında ise 20.0 olmuş ve bu değerler istatistiki olarak önemli farklılıklar meydana getirmiştir. En düşük çimlenme indeksi değeri 35.1 ile Victoria çeşidinden elde edilirken en yüksek çimlenme indeksi değeri ise 85.3 ile MA-414 çeşidinden elde edilmiş ve ortalama çimlenme değerleri arasındaki farklllı istatistiki olarak önemli bulunmuştur. 
Kontrol uygulamasında 81.2 olan çimlenme indeksi -3 PEG kuraklık stresinde 89.9'a yükselmiş, -6 PEG kuraklık stresinde ise 20.0'a düşmüş ve bu değişim istatistiksel olarak önemli olmuştur.

Feng ve ark. (2018) yaptıkları çalışmada çimlenme indeksi \%5 PEG uygulamasına kadar yükseldiği ve artan kuraklık stresi ile de çimlenme indeksinin düşmeye başladığını bildirmişlerdir. MA-414 ve Ezzelina çeşitlerinin çimlenme indeksi bakımından diğer çeşitlere göre daha üstün olduğunun söylemek mümkündür. Çimlenme indeksi hesaplamasında her gün çimlenen tohum sayısı kullanılmakta ve bu parametre iyi ve hızlı bir çıkış oluşturabilme potansiyeli olan çeşitlerin belirlenmesinde önemli bir kriterdir. Yonca tesisinde ekilen tohumların hızlı bir şekilde çimlenmesi ve fidelerin tarlaya yerleşmesi tesisin devamlılığı ve verim potansiyeli açısından önemlidir. Nispeten kurak şartlarda veya ekimden sonra meydana gelen kuraklık şartlarında ve daha da önemlisi sulama sıkıntısının olduğu durumlarda hızlı bir çıkış ve fide oluşumu daha da önem kazanmaktadır.

Çizelge 3. Araştırmadan elde edilen çimlenme ve vigor indeksi

\begin{tabular}{|c|c|c|c|c|c|c|c|c|}
\hline \multirow[b]{2}{*}{ Çeşitler } & \multicolumn{4}{|c|}{ Vigor index } & \multicolumn{4}{|c|}{ Çimlenme İndeksi } \\
\hline & Kontrol & 3 bar & 6 bar & Ort. & Kontrol & $3 \mathrm{bar}$ & 6 bar & Ort. \\
\hline Bilensoy-80 & $41.7 \mathrm{~b}^{*}$ & $16.2 \mathrm{gh}$ & $1.1 \mathrm{k}$ & $23.1 \mathrm{~cd}^{1}$ & $82.7 \mathrm{e}^{-} \mathrm{m}^{*}$ & $95.0 \mathrm{c}-\mathrm{h}$ & 33.3 qrs & $70.3 \mathrm{bcd}^{2}$ \\
\hline Derby & $30.7 \mathrm{~cd}$ & $18.6 \mathrm{fg}$ & $0.1 \mathrm{k}$ & $17.7 \mathrm{efg}$ & $111.3 \mathrm{bc}$ & $96.3 \mathrm{c}^{-} \mathrm{g}$ & $10.0 \mathrm{uv}$ & $72.5 \mathrm{bcd}$ \\
\hline Elçi & $43.3 \mathrm{~b}$ & $20.6 \mathrm{efg}$ & $0.0 \mathrm{k}$ & $24.9 b c$ & $72.0 \mathrm{j}-\mathrm{o}$ & $94.6 \mathrm{c}-\mathrm{h}$ & $0.0 \mathrm{v}$ & 55.6 ef \\
\hline Escorial & $33.6 \mathrm{c}$ & $23.4 \mathrm{ef}$ & $0.8 \mathrm{k}$ & $16.3 \mathrm{fg}$ & $78.7 \mathrm{~g}-\mathrm{m}$ & $110.0 \mathrm{bc}$ & $29.7 \mathrm{q}^{-\mathrm{t}}$ & $72.8 \mathrm{bcd}$ \\
\hline Ezzelina & $41.2 \mathrm{~b}$ & $20.0 \mathrm{efg}$ & $0.1 \mathrm{k}$ & 19.5 ef & $86.0 \mathrm{e}^{-\mathrm{k}}$ & $135.3 \mathrm{a}$ & $6.3 \mathrm{v}$ & $75.9 \mathrm{~b}$ \\
\hline Fito Altiva & $30.3 \mathrm{~cd}$ & $10.1 \mathrm{ij}$ & $0.3 \mathrm{k}$ & $16.8 \mathrm{fg}$ & $116.0 \mathrm{~b}$ & $75.7 \mathrm{~h}-\mathrm{m}$ & $28.0 q^{-} u$ & $73.2 \mathrm{bcd}$ \\
\hline Frigos & $44.2 \mathrm{~b}$ & $31.7 \mathrm{c}$ & $1.1 \mathrm{k}$ & $27.9 b$ & $76.7 \mathrm{~g}-\mathrm{m}$ & $94.7 \mathrm{c}-\mathrm{h}$ & $39.7 \mathrm{pq}$ & $70.3 \mathrm{bcd}$ \\
\hline İside & $39.5 \mathrm{~b}$ & $31.4 \mathrm{c}$ & $0.7 \mathrm{k}$ & $20.6 \mathrm{de}$ & $92.7 \mathrm{c}^{-1}$ & $111.3 \mathrm{bc}$ & $17.0 \mathrm{r}^{-} \mathrm{v}$ & $73.7 b c$ \\
\hline MA-414 & $21.4 \mathrm{e}^{-\mathrm{g}}$ & $11.8 \mathrm{hlj}$ & $1.7 \mathrm{k}$ & $8.9 h$ & $107.7 \mathrm{bcd}$ & 71.7 j-o & $76.7 \mathrm{~g}-\mathrm{m}$ & $85.3 \mathrm{a}$ \\
\hline Magna 601 & $5.7 \mathrm{jk}$ & $7.8 \mathrm{j}$ & $0.0 \mathrm{k}$ & $2.6 i$ & 66.3 l-o & $67.7 \mathrm{k}-\mathrm{o}$ & $0.0 \mathrm{v}$ & $44.7 \mathrm{~g}$ \\
\hline Nimet & $40.4 \mathrm{~b}$ & $23.7 \mathrm{ef}$ & $1.3 \mathrm{k}$ & $14.3 \mathrm{~g}$ & $83.0 \mathrm{e}^{-} \mathrm{m}$ & $80.0 \mathrm{e}^{-\mathrm{m}}$ & $15.0 \mathrm{~s}^{-} \mathrm{v}$ & $59.3 e$ \\
\hline Plato & $40.4 \mathrm{~b}$ & $24.3 \mathrm{ef}$ & $0.2 \mathrm{k}$ & $23.3 \mathrm{~cd}$ & $81.7 \mathrm{e}^{-\mathrm{m}}$ & $98.7 \mathrm{~b}-\mathrm{f}$ & $7.7 \mathrm{v}$ & $62.7 \mathrm{de}$ \\
\hline Prosementi & $40.6 \mathrm{~b}$ & $24.3 \mathrm{ef}$ & $1.9 \mathrm{k}$ & $16.7 \mathrm{fg}$ & $96.3 \mathrm{c}^{-} \mathrm{g}$ & $90.0 \mathrm{~d}-\mathrm{j}$ & $33.7 \mathrm{qr}$ & $73.3 \mathrm{bcd}$ \\
\hline Queen & $42.6 \mathrm{~b}$ & $25.2 \mathrm{de}$ & $0.9 \mathrm{k}$ & $26.2 b c$ & $73.3 \mathrm{I}^{-n}$ & $84.3 \mathrm{e}-1$ & $16.3 \mathrm{r}^{-\mathrm{v}}$ & $58.0 e$ \\
\hline Sabrina & $54.5 \mathrm{a}$ & $39.5 \mathrm{~b}$ & $1.6 \mathrm{k}$ & $31.8 \mathrm{a}$ & 56.3 nop & $93.3 \mathrm{c}-\mathrm{h}$ & $26.3 q^{-} u$ & $58.7 e$ \\
\hline Savaş & $44.6 \mathrm{~b}$ & $42.2 \mathrm{~b}$ & $0.9 \mathrm{k}$ & $25.5 b c$ & $81.0 \mathrm{e}^{-\mathrm{m}}$ & 99.7 b-e & 11.3 tuv & 64.0 cde \\
\hline Sünter & 15.9 hgl & $9.7 \mathrm{j}$ & $0.0 \mathrm{k}$ & $8.4 h$ & $63.6 \mathrm{mno}$ & $77.3 \mathrm{~g}-\mathrm{m}$ & $2.0 \mathrm{v}$ & $47.7 \mathrm{fg}$ \\
\hline Victoria & $10.7 \mathrm{hij}$ & $8.6 \mathrm{j}$ & $0.0 \mathrm{k}$ & $6.4 \mathrm{~h}$ & 53.7 op & $44.0 \mathrm{pq}$ & $7.7 \mathrm{v}$ & $35.1 \mathrm{~h}$ \\
\hline Ortalama & $32.3 A^{+}$ & $21.6 B$ & $0.7 C$ & & $81.2 \mathrm{~B}^{+}$ & $89.9 A$ & $20.0 C$ & \\
\hline
\end{tabular}

*Aynı sütun içerisinde benzer harf ile gösterilen ortalamalar. Duncan testine göre. $\mathrm{P} \leq 0.01$ hata sinırları içerisinde birbirlerinden farksizdir.

+Aynı satır içerisinde benzer harf ile gösterilen ortalamalar. Duncan testine göre. $\mathrm{P} \leq 0.01$ hata sınırları içerisinde birbirlerinden farksizdir.

1 Aynı sütun içerisinde benzer harf ile gösterilen ortalamalar. Duncan testine göre. $\mathrm{P} \leq 0.01$ hata sinırları içerisinde birbirlerinden farksizdir

\section{Çimlenme Hizı}

Araştırmada incelenen çeşitlerin çimlenme hızı değerlerine uygulanan varyans analiz sonuçlarına göre incelenen çeşitler arasında çok önemli farklılıklar bulunmuştur (Çizelge 4). Ortalama çimlenme hızları 4.4 ile 24.4 arasında değişiklik göstermiş ve bu değişim istatistiki olarak çok önemli derecede farklılık göstermiştir $(\mathrm{P} \leq 0.01)$.

Çeşitlerin ortalama çimlenme hızı en düşük Victoria, Sünter ve Magna 601 çeşitlerinden elde edilmiştir (sırasıyla 5.6, 5.6 ve 4.4). En yüksek çimlenme hızı Sabrina çeşidinden (24.4) elde edilmiştir. Çeşitlere uygulanan farklı kuraklık streslerinden elde edilen ortalama değerler arasında önemli derecede farklılık vardır ve bu farklılık istatistiksel olarak önemli olmuştur. Safarnejad (2008)'a göre çimlenme hızı artan kuraklık stresi seviyelerinde oldukça azalma göstermiş ve -1.2 MPa'da en düşük değere ulaşmıştır.
Kontrol uygulamasında 24.5 olan çimlenme hızı -3 bar PEG konsantrasyonunda 15.7, -6 bar Peg konsantrasyonunda ise 0.8 olmuş ve bu değişim istatistiki olarak önemli derecede birbirinden farklılık göstermiştir. Benzer bulgular Safarnejad (2008), Tilaki ve ark. (2009), ve Hamidi ve Safarnejad (2010) tarafından da elde edilmiştir. Çimlenme hızının hesaplanmasında kullanılan değer çimlenen tohum sayıları olduğundan çimlenme hızı ve çimlenme oranı değerleri birbiri ile uyum içerisindedir. Çimlenme indeksinde olduğu gibi çimlenme hızı hesaplamasında da kullanılan parametre çimlenen tohum sayılarıdır. Bundan dolayı çimlenmenin hızlı olması ve bunun kuraklık ve/veya sulama sıkıntısı olan zamanlarda meydana gelen kuraklık stresinden etkilenmemesi iyi bir yonca tesisi oluşturmada ve çeşit seçiminde önemli bir göstergedir. 
Çizelge 4. Araştırmadan elde edilen ortalama çimlenme hızı (gün)

\begin{tabular}{|c|c|c|c|c|}
\hline \multirow[b]{2}{*}{ Çeşitler } & \multicolumn{4}{|c|}{ Çimlenme Hızı } \\
\hline & Kontrol & $3 \mathrm{bar}$ & 6 bar & Ort. \\
\hline Bilnsoy-80 & $23.2 \mathrm{gh}^{*}$ & 10.5 no & $1.1 \mathrm{r}$ & $11.6 f^{1}$ \\
\hline Derby & $12.4 \mathrm{mno}$ & $13.1 \mathrm{mn}$ & $0.3 \mathrm{r}$ & $8.6 g$ \\
\hline Elçi & $37.6 \mathrm{~b}$ & $23.3 \mathrm{gh}$ & $0.0 \mathrm{r}$ & $20.3 \mathrm{~b}$ \\
\hline Escorial & $30.4 \mathrm{~cd}$ & $16.7 \mathrm{kl}$ & $1.0 \mathrm{r}$ & $16.1 d$ \\
\hline Ezzelina & $31.3 \mathrm{c}$ & $14.8 \mathrm{~lm}$ & $0.2 \mathrm{r}$ & $15.4 \mathrm{de}$ \\
\hline Fito Altiva & $19.2 \mathrm{jk}$ & $7.3 \mathrm{pq}$ & $0.9 \mathrm{r}$ & $9.1 \mathrm{~g}$ \\
\hline Frigos & $35.4 \mathrm{~b}$ & $23.8 \mathrm{fg}$ & $1.6 \mathrm{r}$ & $20.3 \mathrm{~b}$ \\
\hline İside & $28.2 \mathrm{de}$ & $17.3 \mathrm{kl}$ & $0.7 \mathrm{r}$ & $15.4 d e$ \\
\hline MA-414 & $14.1 \mathrm{~m}$ & 9.8 op & $2.3 \mathrm{r}$ & $8.7 \mathrm{~g}$ \\
\hline Magna 601 & $6.2 \mathrm{o}$ & $6.9 \mathrm{q}$ & $0.0 \mathrm{r}$ & $4.4 \mathrm{~h}$ \\
\hline Nimet & $29.9 \mathrm{~cd}$ & $24.2 \mathrm{fg}$ & $1.3 \mathrm{r}$ & $18.5 c$ \\
\hline Plato & $25.5 \mathrm{fg}$ & $17.4 \mathrm{kl}$ & $0.2 \mathrm{r}$ & $14.4 e$ \\
\hline Prosementi & $20.7 \mathrm{hij}$ & $12.5 \mathrm{mno}$ & $1.4 \mathrm{r}$ & $11.5 f$ \\
\hline Queen & $30.2 \mathrm{~cd}$ & $23.5 \mathrm{~g}$ & $1.2 \mathrm{r}$ & $18.3 c$ \\
\hline Sabrina & $45.2 \mathrm{a}$ & 26.4 ef & $1.6 \mathrm{r}$ & $24.4 a$ \\
\hline Savaş & $32.3 \mathrm{c}$ & $20.6 \mathrm{ij}$ & $0.7 \mathrm{r}$ & $17.8 c$ \\
\hline Sünter & 9.7 op & $7.0 \mathrm{pq}$ & $0.1 \mathrm{r}$ & $5.6 h$ \\
\hline Victoria & $9.7 \mathrm{op}$ & $6.8 \mathrm{q}$ & $0.2 \mathrm{r}$ & $5.6 \mathrm{~h}$ \\
\hline Ortalama & $24.5 A^{+}$ & $15.7 B$ & $0.8 C$ & \\
\hline
\end{tabular}

*Aynı sütun içerisinde benzer harf ile gösterilen ortalamalar. Duncan testine göre. $\mathrm{P} \leq 0.01$ hata sinırları içerisinde birbirlerinden farksızdır.

+Aynı satır içerisinde benzer harf ile gösterilen ortalamalar. Duncan testine göre. $\mathrm{P} \leq 0.01$ hata sinırları içerisinde birbirlerinden farksızdır.

1 Aynı sütun içerisinde benzer harf ile gösterilen ortalamalar. Duncan testine göre. $\mathrm{P} \leq 0.01$ hata sinırları içerisinde birbirlerinden farksızdır.

\section{SONUÇ}

Araştırmadan elde edilen sonuçlara göre çimlenme oranları kontrole göre -3 bar kuraklık stresinde \%9.96, -6 bar kuraklık stresinde \%88.6 oranında azalmıştır. Yonca tohumlarının eski veya taze olması, kaplı veya çılak olması gibi etkenler çimlenme oranının düşük olmasina neden olan etkenlerdendir. $\mathrm{Bu}$ yüzden çimlenme yüzdesi başarılı bir yonca tesisi için en önemli hususlardan biridir. Bunun yanında incelenen diğer özelliklerin hesaplanmasında da çimlenme oranının kullanılması çeşit seçiminde çimlenme oranının önemini bir kez daha ortaya koymaktadır. Bu hususlar dikkate alındığında incelenen çeşitler arasinda Sabrina, ve Frigos gibi yeni tescil edilen çeşitler yanında 1983 yılında üretim izni alan çok eski bir çeşit olan Elçi çeşitlerinin çimlenme oranlarına göre erken gelişme döneminde kuraklık stresine toleranslı olduğu, Magna 601, Victoria ve Sunter çeşitlerinin ise kuraklık stresine toleranslı olmadığı belirlenmiştir. İncelenen bütün karakterler dikkate alındığında Sabrina kuraklık stresine en toleranslı çeşit olarak değerlendirilebilir. Sulama imkanlarının kısıtlı olduğu bölgelerde tavsiye edilebilecek bu çeşidin, kurak ve kısıtlı sulamanın olduğu bölgelerde tarla denemelerine dahil edilmesi, bu bölgelerde yonca üretimini geliştirilmesine katkı sağlayacaktır.

\section{KAYNAKLAR}

Carmen D, Nedelea G 2012. The Effect of Genotype And Water Stress on Germination Ability of Seeds in Some Alfalfa Varieties. Journal of Horticulture, Forestry and Biotechnology, 16(1):153-156.

Çarpıcı Budaklı E, Erdel B 2015. Determination of Responses of Different Alfalfa (Medicago sativa L.) Varieties to Salt Stress at Germination Stage. YYÜ Tarım Bilimleri Dergisi 26: 61-67.

Feng J, Wang D, Shao C, Zhang L. Tang X 2018. Effects of Cold Plasma Treatment on Alfalfa Seed Growth Under Simulated Drought Stress. Plasma Science and Technology. 20 (3): 35-50.

Hamidi H 2000. Experiment on Alfalfa to Measure its Tolerance to Drought Using Texture Culture Technique. M.A. Agriculture Thesis, Agriculture University, Tarbiat Modares University, pp: 154.

Hamidi H, Safarnejad A 2010. Effect of Drought Stress on Alfalfa Cultivars (Medicago sativa L.) in Germination Stage. American-Eurasian Journal of Agricultural Environmental Sciences 8(6): 705-709.

Kalefetoğlu T, Ekmekçi Y 2005. The Effect of Drought on Plant Sand Tolerance Mechanisms. Gazi University. Journal of Science, 18 (4): 723- 740.

Kaplan Ş, Güçlü Ş, Baytekin G, Tiryaki İ 2015. Yonca (Medicago sativa L.) ve Çayır Üçgülü (Trifolium pratense L.) Tohumlarinın Tuz Ve Kuraklık Stresine Verdikleri Tepkilerin Belirlenmesi. Türkiye 11. Tarla Bitkileri Kongresi, 7-10 Eylül , Çanakkale.

Özkurt M 2018. Tokat-Kazova Ekolojik Koşullarında Farklı Sira Arası ve Tohumluk Miktarlarının Yonca (Medicago sativa L.)'da Ot Verimi ve Kalite Karakterleri Üzerine Etkileri. Tokat Gaziosmanpaşa Üniversitesi Fen Bilimleri Enstitüsü, Tarla Bitkileri Ana Bilim Dall, (Doktora Tezi). Tokat, $141 \mathrm{~s}$.

Safarnejad A 2008. Morphological and Biochemical Response to Osmotic Stress in Alfalfa (Medicago sativa L.). Pak. J. Bot., 40(2): 735-746.

Saxena RC, Harshan V, Saxena A, Sukumaran P, Sharm, MC, Lakshaman Kumar M 1993. Larvicidal and Chemosterilant Activity of Annona Squamosa Alkaloids Against Anopheles Stephensi. Journal of the American Mosquito Control Association. (9): 8497.

Soltani A, Khodarahmpour Z, Jafar A A, Nakhjavan S 2012. Selection of Alfalfa (Medicago sativa L.) Cultivars for Salt Stress Tolerance Using Germination Indices. African Journal of Biotechnology, 11(31):7899-7905.

Tilaki GAD, Behtari. B 2009. Effect of Salt and Water Stress on the Germination of Alfalfa (Medicago Sativa L.) Seed 2: 158-164.

Torabi M, Halim RA, Sinniah UR, Choukan R 2011. Influence of Salinity on The Germination of Iranian Alfalfa Ecotypes. African Journal of Agricultural Research. 6(19): 4624-4630. 